https://doi.org/10.15407/ujpe66.7.630

I.N. YAKOVKIN

Institute of Physics, Nat. Acad. of Sci. of Ukraine

(46, Prosp. Nauky, Kyiv 03028, Ukraine; e-mail: yakov@iop.kiev.ua)

\title{
SURFACE AND INTERFACE BANDS OF THE CdTe-HgTe-CdTe HETEROSTRUCTURE: EVIDENCE OF METALLICITY
}

\begin{abstract}
Performed full-relativistic DFT calculations have demonstrated that thin HgTe layers are metallic and, with increasing thickness, do not become insulators - either ordinary band insulators or topological insulators. The variations of the potential at the CdTe-HgTe interfaces are found to be negligible in comparison with those at the terminating surfaces of the CdTe$\mathrm{HgTe}-\mathrm{CdTe}$ films, so that the interfaces in fact do not form any potential well. It is shown that the interface-related bands of the $\mathrm{CdTe}-\mathrm{HgTe}-\mathrm{CdTe}$ films are situated well below $\mathrm{E}_{F}$, so that a dominant input into the density of states at $E_{F}$ and, therefore, to the conductivity is provided not by the interface states, but by the surface bands of the net layered system. It is reasonable therefore to consider an alternative interpretation of the reported thickness dependence of the conductivity of the system, such as the possible surface segregation of components or unavoidable contaminations, which seems much more realistic than the interpretation based on involving topological insulators and topologically protected surface states.
\end{abstract}

Keywords: surface states, density functional calculations, $\mathrm{HgTe}-\mathrm{CdTe}$ layers.

\section{Introduction}

The discovery of the quantum Hall effect [1] initiated a dramatic increase of the interest in properties of thin films, in particular, electronic surface states of two-dimensional (2D) insulators. Since the application potential of the quantum Hall effect is restricted by the requirement of a large magnetic field, a new class of topological states called quantum spin Hall (QSH) states or topological insulators (TI) was emerged [2-9]. In contrast to the quantum Hall effect, the spin separation in the QSH phase does not require any external magnetic field and is attributed to the spin-orbit coupling (SOC) and the special topological order of a $2 \mathrm{D}$ system. In particular, it was proposed that the QSH phase is a time reversal invariant electronic state with a bulk electronic band gap that supports the transport of a charge and a spin

(c) I.N. YAKOVKIN, 2021 in gapless edge states. These edge states (or surface states in $3 \mathrm{D}$ ) were suggested to be topologically protected and, thus, insensitive to the weak disordering and interactions in the system. The most important prediction of the developed theory was the possibility to get a spin current by means of surface states without the dissipation.

The concept of TI was supported by reports on the experimental evidence of the appearance of the QSH phase in HgTe layers sandwiched between CdTe layers [6-9]. Thus, it was suggested that thin layers of HgTe behave themselves like an ordinary ("band") insulator because of an influence of the CdTe covering films which dictate its electronic structure to the HgTe film, while for thicker films (more than $70 \AA$ ), this influence effectively diminishes, and, therefore, the HgTe layers suddenly become TI. It should be noted that this interpretation treats the $\mathrm{CdTe}-\mathrm{HgTe}-$ CdTe quantum wells as insulators with well separated

ISSN 2071-0194. Ukr. J. Phys. 2021. Vol. 66, No. 7 
valence and conduction bands (which is mandatory for the existence of the QSH phase, i.e., topological insulator), with topologically protected gapless edge states, somehow appeared for thicker HgTe films.

The discovery of the QSH state in CdTe- $\mathrm{HgTe}$ CdTe quantum wells has been of an enormous importance for the emerging search for other QSH materials. However, calculations of the electronic structure performed so far [9-13] have not finally resolved certain discrepancies in the interpretation of the experiments, and applications of the theory (in particular, topology) to this system arise serious questions to be clarified. Küfner and Bechstedt [10] performed the DFT study of the edge states of HgTe quantum wells and qualitatively verified the previous result obtained by Bernevig et al. [6] using a four-band $k \cdot p$ approach. In contrast, Luo and Zunger [11], using an atomistic pseudopotential method, showed that the topological states of the $\mathrm{HgTe} / \mathrm{CdTe}$ heterostructure are two-dimensional (2D) interface states, instead of $1 \mathrm{D}$ edge states as suggested in [6].

The main purpose of the present article is to attract attention to a certain doubt concerning the applicability of the concept of topological insulators to real surfaces. With this aim, we have performed fullrelativistic (i.e., with account for the spin-orbit coupling) DFT/LDA calculations of electronic structures of HgTe and CdTe bulk crystals and films with an accent on surface bands, which have been found crucial for the formation of the electronic structure of the layered system.

\section{Methods}

The calculations were performed with the ABINIT set [14] using the plane-wave decomposition of the wave functions with Troullier-Martins [15] normconserving pseudopotentials. The local density approximation (LDA) exchange-correlation potential was taken in the Goedecker-Teter-Hutter form [16]. The surface Kohn-Sham band structures were computed using the supercell (repeated slab) model with the vacuum gap about $10 \AA$. The non-shifted (i.e., including $\Gamma$ point) $6 \times 6 \times 1$ lattice of $k$-points for the slab and $6 \times 6 \times 6$ for bulk calculations and the energy cutoff of $24 \mathrm{Ha}$ provided the $10^{-4} \mathrm{Ha}$ convergence of the total energy. The standard (Broydentype) [14] structural optimization was performed in all cases until the forces on atoms became below
$0.05 \mathrm{eV} / \AA$, which allowed the determination of atomic positions with an accuracy of $0.02 \AA$.

The quality of chosen pseudopotentials was further verified by means of calculations of the lattice constants of equilibrated bulk crystals with the zincblende structure (which is a diamond-type structure with two fcc lattices $1 / 4$ shifted along the cube diagonal). In particular, the estimated lattice constant for CdTe was found to be of $6.47 \AA$, which is consistent with the experimental value $6.48 \AA$. For $\mathrm{HgTe}$, the optimized lattice constant was $6.43 \AA$, which is slightly (by $3.5 \%$ ) less than the experimental $6.66 \AA$. Surface states/resonances were distinguished by significant weights of wave functions at surface atoms, which can be characterized by a relative electronic charge of outermost surface layers. In the present study, the surface states are defined as those having more than $50 \%$ localization at surfaces. The surface weights for every band and $k$-point were estimated by the integration of the partial local electron density within atomic spheres.

\section{Results and Discussion}

It has been a common practice to present the energy diagrams for heterostructures like if the building blocks had the electronic structure of a bulk material. For example, in the schemes presented in [5-8] for the $\mathrm{CdTe}-\mathrm{HgTe}-\mathrm{CdTe}$ layered system, the $\mathrm{HgTe}$ semiconductor layer lies in the quantum well built by potential barriers induced by the relatively wider energy gap of confining CdTe films. The reader might learn that thin HgTe films are insulators with a "normal ordering of the bands", dictated by the electronic structure of confining CdTe layers, but transform into insulators with an "inverted band ordering" [17-20] pertinent, as suggested in [5-8], to HgTe layers free of the CdTe influence for sufficiently thick films. Thus, it was suggested that, in bulk CdTe, the band ordering is normal, because, like in many other semiconductors with zinc blende structure, the $s$ band lies above $E_{F}$, while the $p$ band is placed below $E_{F}$, forming the conductive and valence bands, respectively. In contrast, in bulk HgTe, the band ordering was suggested to be inverted due to the strong spin-orbit coupling, which apparently agrees with the general mechanism for finding topological insulators $[5,6]$.

This scheme is really confusing. Indeed, while CdTe bulk crystals are semiconductors, HgTe bulk crystals 


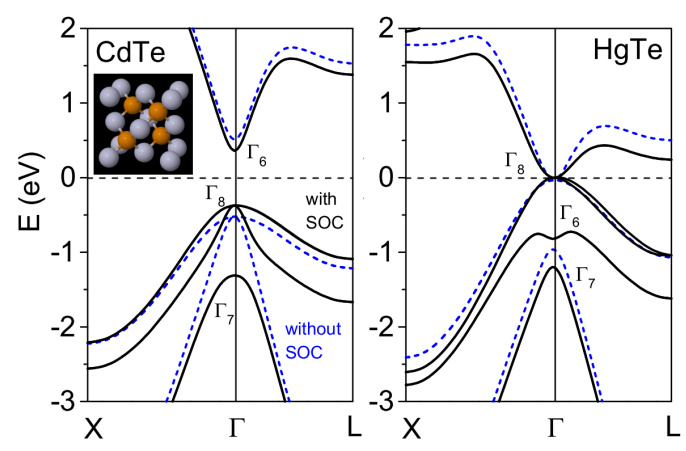

Fig. 1. Relativistic band structures of CdTe and HgTe crystals. Dash blue lines show bands calculated without SOC
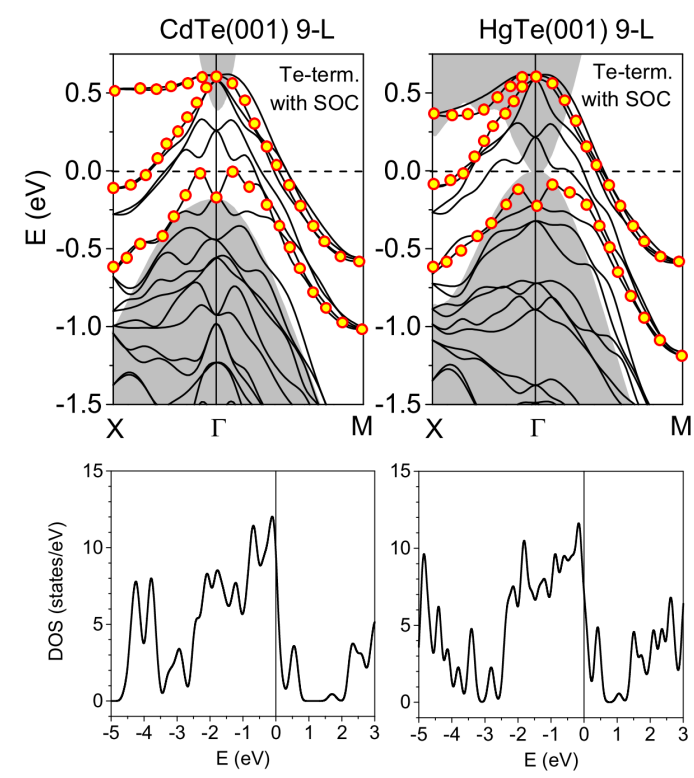

Fig. 2. Surface bands (marked by red-yellow circles) and DOS of 9-layer (001) CdTe and HgTe films with Te-terminated surfaces. The shaded areas show projections of the bulk band structures. The bands crossing $E_{F}$ and related significant DOS at $E_{F}$ prove the metallicity of the film

are metals (or semimetals, because of a rather low density of states (DOS) at $E_{F}$ ), as is evident from the calculated Kohn-Sham band structures shown in Fig. 1. (It should be noted that, for bulk CdTe, the experimental band gap is of $1.5-1.6 \mathrm{eV}$, while present calculations of the optimized CdTe lattice constant give $1.03 \mathrm{eV}$ without the spin-orbit coupling and $0.74 \mathrm{eV}$ with SOC; such underestimation of gaps in DFT is well-known - a brief review can be found in [21].) Evidently, there is no any energy gap in $\mathrm{HgTe}$,

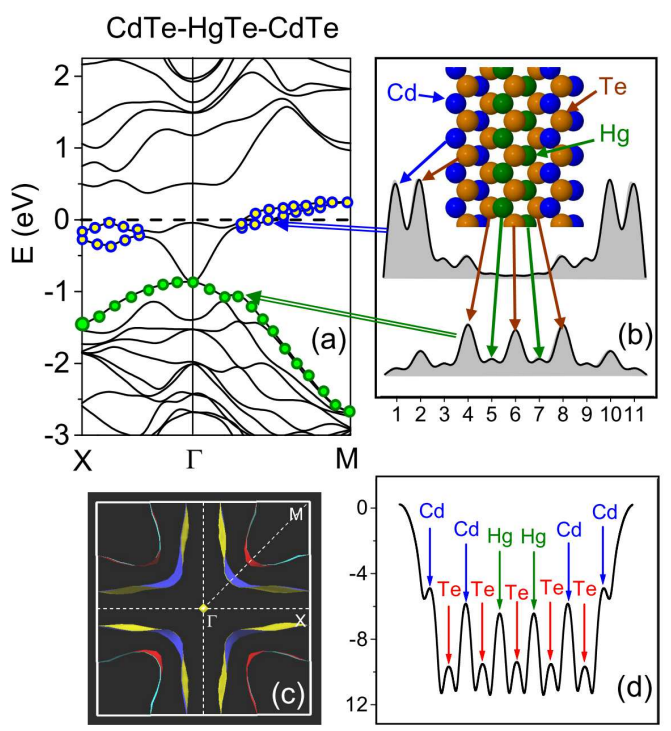

Fig. 3. Band structure of the layered CdTe-HgTe-CdTe system $(a)$. Electron density distribution in surface and interface states $(b)$. Fermi surface of the layered CdTe-HgTe-CdTe system $(c)$. Potential energy distribution along the normal to the surface $(d)$. Green circles in $(a)$ and arrows indicate interface states (i.e., located predominantly on interface Te atoms), while yellow-blue circles mark surface states of the net $\mathrm{CdTe}-$ $\mathrm{HgTe}-\mathrm{CdTe}$ system

so it is of no sense speaking about the band inversion because of a strong band hybridization. The SOC only slightly changes the main character of the $\mathrm{HgTe}$ band structure (as can be seen in Fig. 1, $b$ by comparing the bands calculated with and without SOC), but does not accomplish the band inversion and does not open a gap.

Hence, the presentation of the $\mathrm{CdTe}-\mathrm{HgTe}-\mathrm{CdTe}$ layered system as a quantum well is irrelevant already because of the intrinsic metallicity of $\mathrm{HgTe}$. It is really strange that this point, well known to physicists working with tellurides, has been completely ignored both in the suggested interpretation of experiments and subsequent theoretical studies. Furthermore, the later first-principles calculations have led to controversial conclusions about the dependence of the electronic structure of $\mathrm{HgTe}$ films on the thickness. Anversa et al. [12] found that the applied biaxial stress or electric field leads to the opening of the band gap in $\mathrm{HgTe}$ films (with inverse band ordering!) which decreases with the film thickness, so that the films approach a metallic state. In turn, Brüne et al. [13]

ISSN 2071-0194. Ukr. J. Phys. 2021. Vol. 66, No. 7 
performed transport studies on a three-dimensional 70-nm- thick HgTe layer, which is strained by the epitaxial growth on a CdTe substrate and suggested that the strain induces a band gap in the otherwise semimetallic HgTe, which, thus, becomes a threedimensional topological insulator.

That is, the less the thickness, the wider the gap. This means that the HgTe film could be a topological insulator, when the film is thin enough to allow the CdTe capping layers produce a sufficient stress to open a gap in the band structure with the inverse band ordering, but thick films must become metallic. Note that this conclusion is just opposite to the interpretation of the behavior of the CdTe- $\mathrm{HgTe}-$ CdTe layered structure suggested in [5-8].

The similarity of surface bands of CdTe and $\mathrm{HgTe}$ films is well seen in Fig. 2, which compares the band structures calculated for 9-layer films with Tetermination. It should be noted that the formed surface bands are very similar despite quite different surface projections of the bulk band structures for CdTe and $\mathrm{HgTe}$. In particular, it is the surface bands crossing $E_{F}$ that provide the metallicity of CdTe films, while a metallic state for $\mathrm{HgTe}$ films could be expected already from a semimetallic bulk electronic structure. Again, the role of the SOC in forming the surface electronic structure is only minor.

The sandwich system built from 2-layer HgTe located between CdTe films is also metallic (Fig. 3), as is evident from the surface bands crossing $E_{F}$. It should be noted that the only surface band crossing $E_{F}$ originates from the surface states located at the CdTe surfaces (shown by blue circles), but not from the interface layers. The other coupled bands crossing $E_{F}$ in a vicinity of $\Gamma$ stem not from surfaces, but from inner states of $\mathrm{HgTe}$, as is evident from the charge distributions across the slab estimated for these bands (Fig. 3, b). There are also two bands related to the $\mathrm{CdTe}-\mathrm{HgTe}$ interfaces (marked by green circles in Fig. 3, a). These bands located in a vicinity of $\Gamma$ lie well below $E_{F}$ and, therefore, cannot provide any conductance of the layered system.

The Fermi surface calculated for the CdTe-HgTeCdTe layered structure (Fig. 3, c) clearly demonstrates that the metallic state of this system is provided by electrons of the peripheral part of the Brillouin zone, which was missed in earlier calculations [6-12], where all attention was focused on the region near point $\Gamma$. Thus, the role of interface states in the creation of conduction channels in this structure is only marginal, if any. Another important feature of the layered structure is the absence of the potential well for HgTe electrons (Fig. 3, d), which was presumed in the interpretation of the properties of the $\mathrm{CdTe}-\mathrm{Hg} \mathrm{Te}-\mathrm{CdTe}$ layered structure to be responsible for the formation of a topological insulator state in thicker $\mathrm{HgTe}$ layers.

\section{Conclusion}

The most important result of the performed calculations is that thin $\mathrm{HgTe}$ layers are metallic and, with increasing thickness, do not become insulators either "band insulators" or topological insulators. Concerning the reported conductivity of the $\mathrm{CdTe}-$ $\mathrm{HgTe}-\mathrm{CdTe}$ structure, it would be reasonable to consider other possibilities of the interpretation, rather than just to suggest the appearance of a topological insulator. Indeed, it is known that HgTe hardly retains stoichiometry, the destruction of which, as well as various impurities, significantly affect the electronic structure [9]. Thus, thicker layers will take longer to be deposited, so the film unavoidably will be more contaminated. The segregation of components (and impurities) can strongly affect the electronic structure, so such interpretation is much more natural than that provided by involving exotic theories.

With this example, we are once again convinced that the agreement between theory and experiment can be apparent. Probably, this drawback results from a certain misunderstanding between theorists and physicists, who have different views and speak different languages. For a theorist, the statement "this is from experiment" usually serves as a decisive argument in the interpretation, while an experimentalist hardy could understand the intricacies of the theory and the significance of accepted assumptions. As a result, theory and experiment tend to spontaneously adjust to each other, and such a synergy sometimes leads to discoveries, which, as my now deceased teacher V.K. Medvedev used to say, should be covered back as soon as possible.

1. K.V. Klitzing, G. Dorda, M. Pepper. New method for high-accuracy determination of the fine-structure constant based on quantized Hall resistance. Phys. Rev. Lett. 45, 494 (1980).

2. C.L. Kane, E.J. Mele. Quantum spin Hall effect in graphene. Phys. Rev. Lett. 95, 226801 (2005). 
3. L. Fu, C.L. Kane. Topological insulators with inversion symmetry. Phys. Rev. B 76, 045302 (2007).

4. S. Murakami. Quantum spin Hall effect and enhanced magnetic response by spin-orbit coupling. Phys. Rev. Lett. 97, 236805 (2006).

5. B.A. Bernevig, S.-C. Zhang. Quantum spin Hall effect. Phys. Rev. Lett. 96, 106802 (2006).

6. B.A. Bernevig, T.L. Hughes, S.-C. Zhang. Quantum spin Hall effect and topological phase transition in HgTe quantum wells. Science 314, 1757 (2006).

7. M. König, H. Buhmann, L.W. Molenkamp, T.L. Hughes, C.-X. Liu, X.-L. Qi, S.-C. Zhang. The quantum spin Hall effect: Theory and experiment. Science 318, 766 (2007).

8. X.-L. Qi, S.-C. Zhang. The quantum spin Hall effect and topological insulators. Physics Today 63, 33 (2010).

9. P. Sengupta, T. Kubis, Y. Tan, M. Povolotskyi, G. Klimeck. Design principles for $\mathrm{HgTe}$ based topological insulator devices. J. Appl. Phys. 114, 043702 (2013).

10. S. Küfner, F. Bechstedt. Topological transition and edge states in HgTe quantum wells from first principles. Phys. Rev. B 89, 195312 (2014).

11. J.-W. Luo, A. Zunger. Design principles and coupling mechanisms in the $2 \mathrm{D}$ quantum well topological insulator HgTe/CdTe. Phys. Rev. Lett. 105, 176805 (2010).

12. J. Anversa, P. Piquini, T.M. Schmidt. First-principles study of $\mathrm{HgTe} / \mathrm{CdTe}$ heterostructures under perturbations preserving time-reversal symmetry. Phys. Rev. B 90 195311 (2014).

13. C. Brüne, C.X. Liu, E.G. Novik, E.M. Hankiewicz, H. Buhmann, Y.L. Chen, X.L. Qi, Z.X. Shen, S.C. Zhang, L.W. Molenkamp. Quantum Hall effect from the topological surface states of strained bulk HgTe. Phys. Rev. Lett. 106, 126803 (2011).

14. X. Gonze, J.-M. Beuken, R. Caracas, F. Detraux, M. Fuchs, G.-M. Rignanese, L. Sindic, M. Verstraete, G. Zerah, F. Jollet, M. Torrent, A. Roy, M. Mikami, Ph. Ghosez, J.-Y. Raty, D.C. Allan. First-principles computation of material properties: The ABINIT software project. Comput. Mat. Sci. 25, 478 (2002).

15. N. Troullier, J.L. Martins. Efficient pseudopotentials for plane-wave calculations. Phys. Rev. B 43, 1993 (1991).

16. S. Goedecker, M. Teter, J. Hutter. Separable dual-space Gaussian pseudopotentials. Phys. Rev. B 54, 1703 (1996).
17. N. Berchenko, M.V. Pashkovskii. Mercury telluride - a zero-gap semiconductor. Usp. Fiz. Nauk 119 (6), 223 (1976).

18. N. Orlowski, J. Augustin, Z. Gołacki, C. Janowitz, R. Manzke. Direct evidence for the inverted band structure of HgTe. Phys. Rev. B 61, R5058(R) (2000).

19. K.-U. Gawlik, L. Kipp, M. Skibowski, N. Orłowski, R. Manzke. HgSe: Metal or semiconductor? Phys. Rev. Lett. 78, 3165 (1997).

20. C. Janowitz, N. Orlowski, R. Manzke, Z. Golacki. On the band structure of HgTe and HgSe - view from photoemission. J. of Alloys and Compounds 328, 84 (2001).

21. I.N. Yakovkin, P.A. Dowben. The problem of the band gap in LDA calculations. Surf. Rev. Lett. 14, 481 (2007).

Received 18.08.20

\section{I.M. Яковкін}

ПОВЕРХНЕВІ ТА ІНТЕРФЕЙСНІ

ЗОНИ ГЕТЕРОСТРУКТУРИ СdTe-HgTe-CdTe: ДОКАЗИ МЕТАЛЕВОСТІ

Проведені повнорелятивістські DFT розрахунки продемонстрували, що тонкі шари $\mathrm{HgTe} є$ металевими і зі збільшенням товщини не можуть стати ізоляторами - ані звичайними, ані топологічними. Варіацї потенціалу на інтерфейсах $\mathrm{CdTe}-\mathrm{Hg} \mathrm{Te}$ виявляються незначними порівняно з тими, що на зовнішніх поверхнях плівок $\mathrm{CdTe}-\mathrm{HgTe}-\mathrm{CdTe}$, так що інтерфейси насправді не утворюють потенціального колодязя. Показано, що інтерфейсні зони плівок $\mathrm{CdTe}-\mathrm{HgTe}-$ $\mathrm{CdTe}$ розташовані набагато нижче $E_{F}$, так що домінуючий внесок у густину станів на $E_{F}$, а отже і на провідність, забезпечується не станами інтерфейсу, а поверхневими зонами всієї шаруватої системи. Тому пропонується розглянути альтернативну інтерпретацію повідомленої залежності провідності системи від товщини, наприклад, можливу поверхневу сегрегацію компонентів або неминучі забруднення, що здається набагато більш реалістичним, ніж інтерпретація, заснована на концепції топологічних ізоляторів.

Ключові слова: поверхневі стани, DFT-розрахунки, HgTe-CdTe шари. 